\title{
Failure risk of recycled aggregates concrete
}

\author{
Frédéric Grondin ${ }^{1, *}$, Menghuan $\mathrm{Guo}^{2}$, Emmanuel Rozière ${ }^{1}$, and Ahmed Loukili ${ }^{1}$ \\ ${ }^{1}$ Institut de Recherche en Génie Civil et Mécanique, GeM-UMR 6183, Centrale Nantes - Université \\ de Nantes - CNRS, 1 rue de la Noe, 44321 Nantes, France \\ ${ }^{2}$ Shenzhen University, 3688 Nanhai Ave, Nanshan Qu, Shenzhen Shi, Guangdong Sheng, China
}

\begin{abstract}
In the sustainable development context, the use of demolition waste increases in the building industry. Recycled aggregates from the demolition of concrete structures are then mixed in new concrete. Furthermore, the performance evaluation of a these recycled aggregate concrete (RAC) mix is not only limited to the determination of its conventional mechanical properties. The failure risk of concrete elements in structures made from RAC needs a comprehensive analysis. For that, a study on the fracture process of RAC has been performed and compared with that of normal concrete of the same structural class. Acoustic emission technique and digital correlation method have been used to follow the cracking process. Also, a new modelling approach for the fracture behaviour of RAC at the mesoscopic scale has been developed. It has taken into account the old attached mortar surrounding recycled aggregates. Results show that RAC has a more brittle behaviour than ordinary concrete and the numerical analysis shows that cracks growth through the recycled aggregates which have brittleness behaviour.
\end{abstract}

\section{Introduction}

With the growing waste disposal crisis and depletion of natural construction materials, the use of recycled aggregate concrete (RAC) has been advocated in the past three decades. In France, the standard NF EN 206-1/CN [1] has authorized the maximum replacement percentage of recycled aggregate according to the aggregate type and the exposure class. Few studies have been performed on the cracking risk of RAC. However, some researchers [2 - 4] have observed that the global failure behaviour of RAC specimens under compression, tension or flexion is similar to that of conventional concrete specimens respectively. Furthermore, the performance evaluation of a concrete mix is not only limited to the determination of its conventional mechanical properties $[5,6]$.

RAC is composed of natural aggregate, recycled aggregate, old residual mortar, old and new interfacial transition zones (ITZs), and cement mortar [7 - 9]. It is admitted that previous cracks exist in recycled aggregate [10]. It was observed that RAC have higher water absorption, lower density and lower particle strength [2, 11, 12]. Since the recycled aggregate is composed of "original aggregate" and old attached mortar, the latter one is usually porous and impairs the properties of recycled aggregate [9]. Etxeberria et al. [8]

\footnotetext{
${ }^{*}$ Corresponding author: frederic.grondin@ec-nantes.fr
} 
suggested that the old attached mortar forms the weakest zone in RAC. According to Poon et al. [13], the loose and porous hydrates are usually found in ITZ of RAC whereas for normal concrete dense hydrates are observed in ITZ.

In order to characterize the failure process into RAC, three-point bending tests have been performed. The Digital Image Correlation (DIC) has been used to follow the cracking at the surface and the acoustic emission (AE) technique to follow the internal cracking. A mesoscopic model has been developed to take into account the old attached mortar surrounding recycled aggregates in order to distinguish the cracks into the matrix, ITZ and aggregates.

\section{Materials and methods}

\subsection{Concrete mixtures and experimental methods}

This study is part of the projects PN RECYBETON, ANR ECOREB and FEDER ECOREB, where the task of defining the mixture proportions was done by other partners [12, 14 - 16]. Concrete mixtures were prepared with Portland cement CEM II/A-L 42.5N, crushed limestone aggregate, and recycled aggregate. Recycled aggregate was obtained by crushing of unknown waste concrete. All mixtures were designed so as to have a compressive strength in the range of 25-30 MPa. Table 1 shows the quantities of constituent materials of the mix design for three types of concrete: $\mathrm{C}-\mathrm{N}-\mathrm{N}$ : concrete without recycled aggregates; $\mathrm{C}-\mathrm{N}-30 \mathrm{R}$ : concrete with $30 \%$ recycled aggregate; $\mathrm{C}-\mathrm{N}-100 \mathrm{R}$ : concrete with $100 \%$ recycled aggregate. This last mixture was used to characterize the intrinsic properties of recycled aggregates into the mortar matrix.

Table 1. Concrete mixtures.

\begin{tabular}{|l|c|c|c|}
\hline Components & C-N-N & C-N-30R & C-N-100R \\
\hline w/c ratio & 0.64 & 0.65 & 0.65 \\
\hline Water $\left(\mathrm{kg} / \mathrm{m}^{3}\right)$ & 180 & 185 & 189 \\
\hline Cement $\left(\mathrm{kg} / \mathrm{m}^{3}\right)$ & 270 & 276 & 282 \\
\hline Sand $0 / 4 \mathrm{~mm}\left(\mathrm{~kg} / \mathrm{m}^{3}\right)$ & 780 & 813 & 806 \\
\hline Ordinary Aggregate $\left(\mathrm{kg} / \mathrm{m}^{3}\right)$ & 1087 & 690 & - \\
\hline Recycled Aggregate $\left(\mathrm{kg} / \mathrm{m}^{3}\right)$ & - & 296 & 864 \\
\hline Limestone filler $\left(\mathrm{kg} / \mathrm{m}^{3}\right)$ & 45 & 31 & 1.4 \\
\hline Superplasticizer $\left(\mathrm{kg} / \mathrm{m}^{3}\right)$ & 1.31 & 1.51 & \\
\hline
\end{tabular}

For the failure test, $100 * 200 * 800 \mathrm{~mm}^{3}$ concrete beams were prepared with an effective span equals to $600 \mathrm{~mm}$ and submitted to a three-point bending test. The beams were notched at midspan with a notch depth of $40 \mathrm{~mm}$. The fracture test of the specimens at the age of 28 days was carried out using a universal testing machine as per RILEM-TMC50 recommendations with the loading cell capacity of $160 \mathrm{kN}$ and servo-hydraulic regulation. The load was controlled by crack mouth opening displacement (CMOD) rate of $0.2 \mathrm{~mm} / \mathrm{s}$. In parallel, the DIC method was used with a digital camera with $50 \mathrm{~mm}$ macro lens to acquire images of resolution $2452 * 2056$ pixels at the rate of one image per second during the load test. The correlation of the stored digital images was performed with the software Vic-2D ${ }^{\circledR}$ by calculating the deformation between the reference image and a deformed image. Also, internal cracking was recorder with the AE technique. The device for the acquisition and signal processing of $\mathrm{AE}$ is consisted of a data acquisition system MISTRAS 8 channels. Each waveform was digitized and stored with AEwin ${ }^{\circledR}$ system. The descriptors were further analyzed and evaluated with Noesis ${ }^{\circledR}$ software. The K-mean method, which 
correlate characteristics of the acoustic signature (amplitude, energy, time period, etc.), was applied in order to define acoustic clusters from the signature of each acoustic emission [17].

\subsection{Mesoscopic model}

The numerical simulation of the three-point bending test has been realized in $2 \mathrm{D}$ under plane stress condition. A mesoscopic mesh was generated in the central part of the beam to take into account the heterogeneity of the material, i.e. aggregate, cement mortar and an effective interface (EI). This EI consists of an average of the properties of the old ITZ, the old attached mortar and the new ITZ. For the rest, a homogeneous mesh with gradual larger element has been incorporated in order to avoid the stress concentration. The macroscopic properties of these parts have been considered as the average properties of concrete. The loading is applied as an incremental vertical displacement of a rigid plate (linearly elastic law) fixed at the top middle of the beam (Figure 1). The mesoscopic part consists in generating aggregate inclusions of different sizes in a random distribution in a mortar matrix [18]. EI is then introduced around recycled aggregates. The aggregate size distribution was defined according to the experimental value for the three kinds of concrete.

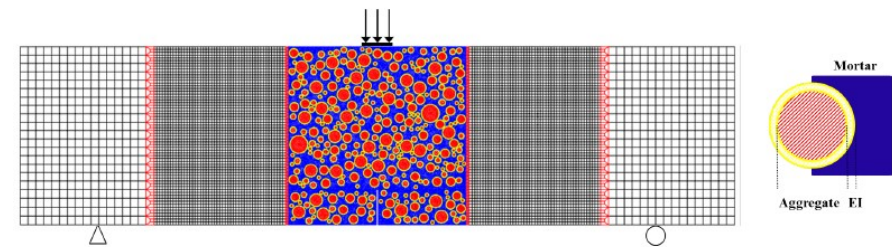

Fig. 1. Meshing and boundary conditions of the concrete beam for a three-point bending test.

The problem formulation consists of a damage elastic behaviour law (2), balance equations (1) and imposed displacements as boundary conditions $(4,5)$ :

$$
\begin{array}{ll}
\underline{\operatorname{div}} \underline{\sigma}(\underline{\mathrm{y}})=\underline{0} & \forall \mathrm{y} \text { in } \mathrm{V} \\
\underline{\sigma}(\underline{\mathrm{y}})=\underline{\mathrm{C}(\mathrm{y}, \underline{\varepsilon}(\underline{\mathrm{y}})): \underline{\varepsilon}(\underline{\mathrm{y}})} & \forall \mathrm{y} \text { in } \mathrm{V} \\
\underline{\varepsilon}(\underline{\mathrm{y}})=1 / 2\left(\operatorname{grad}(\underline{\mathrm{u}})+{ }^{\mathrm{t}} \operatorname{grad}(\underline{\mathrm{u}})\right) & \forall \underline{y} \text { in } \mathrm{V} \\
\underline{\mathrm{F}}=\underline{\sigma}(\underline{\mathrm{y}}) \cdot \underline{\mathrm{n}} & \forall \underline{y} \text { in } \Gamma_{1} \\
\underline{\mathrm{u}}=\underline{\mathrm{U}} & \forall \underline{y} \text { in } \Gamma_{2}
\end{array}
$$

where $\underline{\sigma}$ represents the stresses field, $\underline{\varepsilon}$ the strains field, $\underline{u}$ the displacement field, $\underline{y}$ the position, $\underline{F}$ the applied force on the surface $\Gamma_{1}$ of unit vector $\underline{\mathrm{n}} \underline{\mathrm{U}}$ the applied displacement on the surface $\Gamma_{2}$, and $\underline{C}(\mathrm{y}, \underline{\varepsilon}(\mathrm{y})): \underline{\varepsilon}(\mathrm{y})$ the secant stiffness tensor depending on the local strains and damage. The isotropic damage model developed by Fichant et al. [19] has been chosen in this study. This model represents the unilateral effect and can be used to obtain objective results independently of the length of the finite elements by controlling the fracture energy. The model is based on the relation between the total stress and the effective stress of the material according to the damage scalar value d [19]:

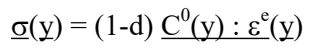

\section{Results analysis}




\subsection{Experimental analysis}

The average load-CMOD curves for the three kinds of concrete are presented in Figure 2 (left). We can observe that the pre-peak response is almost identical for normal concrete and RAC. The DIC method gives more information on the cracking process (Figure 2 (right)) by following the fracture length during the loading time from $60 \%$ of the maximum loading to $20 \%$ of the maximum after peak. In RAC, crack opening starts at a lower loading step as compared to normal aggregate concrete. Moreover, the crack development is faster in RAC. It shows that RAC are more concerned by the cracking risk under service loadings. Moreover, faster crack development in such concrete may lead to catastrophic failures. Higher strain gradients observed in the localized damage zone in RAC could be due to strong discontinuities or existing cracks in recycled aggregate.
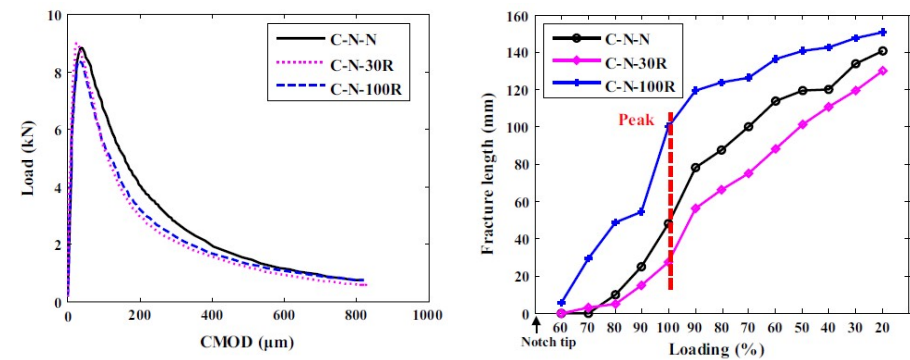

Fig. 2. Load-CMOD curves (left). Fracture length (right).

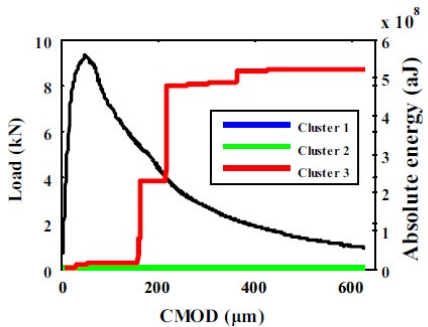

(a)

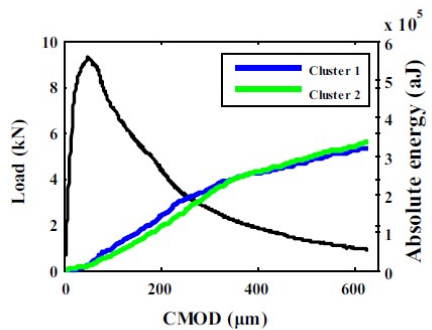

(c)

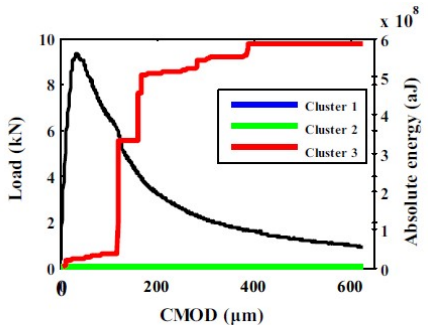

(b)

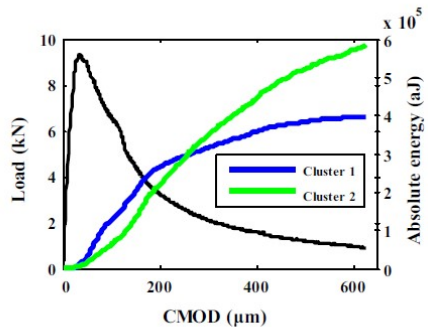

(d)

Fig. 3. Load-CMOD curve and cumulated absolute energy of each cluster for (a) $\mathrm{C}-\mathrm{N}-\mathrm{N}$ and (b) $\mathrm{C}-\mathrm{N}-$ 100R; zoom of Cluster 1 and Cluster 2 for (c) C-N-N and (d) C-N-100R. 
By applying $\mathrm{AE}$ classification method, three clusters with different $\mathrm{AE}$ features are discriminated for both normal and RAC (Figure 3). The specific characteristics of each cluster define micro-fracture phenomena occurring during the failure process. It can be concluded that in case of RAC, the leading micro-fracture phenomenon is ITZ cracking. Also the micro-fractures (all phases) are more localized and intense as compared to normal concrete. It indicates a weak bond between mortar and recycled aggregate which would be the principal cause of failure of recycled concrete structures.

\subsection{Numerical analysis}

Figure 4 shows the numerical results of the failure simulation. Mechanical properties of mortar and ordinary aggregates were calibrated on the measurements of C-N-N. Then, assumptions were made for the recycled aggregate properties in order to obtain the good comparison for C-N-100R. Finally, without other calibrations, the beam C-N-30R was simulated in a good agreement with the experimental measurements. It was done in order to help the experimental analysis with the possibility to follow the cracking process at the mesoscopic scale, but not with a predictive modelling objective. In the modelling, the damage will not occur in recycled aggregate if its resistance is higher than that of the cement mortar due to the high stress concentration in the very thin EI while it is not always the case in actual experiment. However, the damage model does provide the possibility to better describe the rupture process of RAC, and it is capable of demonstrating the roles of the different phases in the material. The numerical results are generally consistent with the experimental observations. Moreover, the influence of old attached mortar on the mechanical behaviour of RAC is explicitly illustrated in the modelling (Figure 5) where we can see that failure occurs mainly on the boundary of aggregates into C-N-30R than into C$\mathrm{N}-\mathrm{N}$. But we can also see that the failure into the two concrete are similar, as observed by the DIC method.
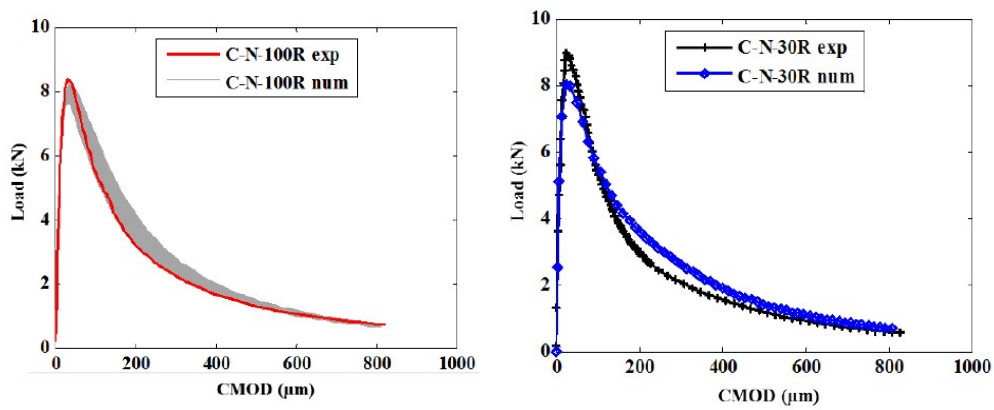

Fig. 4. Comparison of the experimental and numerical Load-CMOD evolution for RAC.

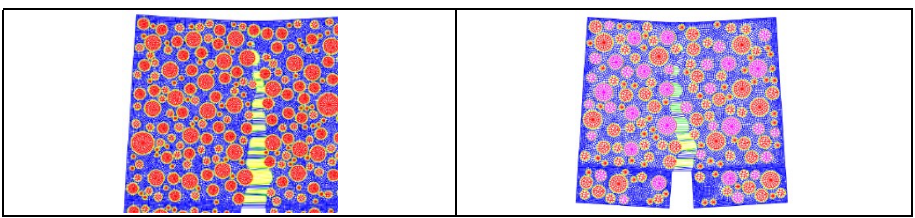

Fig. 5. Numerical diagrams of the crack opening at the end of the rupture for C-N-N (left) and C-N30R (right). 


\section{Conclusions}

The fracture behaviour of recycled aggregate concrete has been compared with normal aggregate concrete. The results clearly indicate that $100 \%$ replacement by recycled aggregate significantly increases the cracking risk. Therefore the complete replacement should be avoided in the construction of structures using RAC. Small portion of recycled aggregate up to $30 \%$ of total aggregate content can be used and no significant effect on the fracture properties and fracture mechanisms has been observed. The numerical analysis of damage shows that in RAC it develops not only in the mortar matrix and in the effective interphase which is the most fragile part, but also in the recycled aggregate. The width of the damage zone decreases with the increasing of the replacement percentage by recycled aggregate.

Support from the French National Research Agency (ANR: Agence Nationale de la Recherche) and the FEDER Pays de La Loire are acknowledged (ECOREB project).

\section{References}

1. NF EN 206/CN (2014).

2. M.Casuccio, M.C.Torrijos, G. Giaccio, R. Zerbino, Constr. Build. Mat. 22 (2008)

3. J. Xiao, W. Li, Y. Fan, X. Huang, Constr. Build. Mat. 31 (2012)

4. G.-F. Belén, M.-A. Fernando, C.L. Diego, S.-P. Sindy, Constr. Build. Mat. 25 (2011)

5. S.P. Shah, S.E. Swartz, C. Ouyang, Fracture mechanics of concrete: applications of fracture mechanics to concrete, rock and other quasi-brittle materials (Wiley, 1995)

6. Z.P. Bazant, J. Planas, Fracture and size effect in concrete and other quasibrittle materials (CRC Press, 1998)

7. V.W.Y. Tam, X.F. Gao, C.M. Tam, Cem. Concr. Res. 35 (2005)

8. M. Etxeberria, E. Vazquez, A. Mari, Mag. Concr. Res. 58 (2006)

9. Z. Zhao, S. Remond, D. Damidot, W. Xu, Constr. Build. Mat. 81 (2015)

10. K.H. Yang, H.S. Chung, A.F. Ashour, ACI Mat. J. 105 (2008)

11. L. Evangelista, J. de Brito, Cem. Concr. Compos. 32, 1 (2010)

12. A.Z. Bendimerad, E. Roziere, A. Loukili, Mat. Struct. 48, 11 (2015)

13. C.S. Poon, Z.H. Shui, L. Lam, Constr. Build. Mat. 18 (2004)

14. G. Wardeh, E. Ghorbel, H. Gomart, Int. J. Concr. Struct. Mat. 9 (2015)

15. S. Omary, E. Ghorbel, G. Wardeh, Constr. Build. Mat. 108 (2016)

16. A.Z. Bendimerad, E. Rozière, A. Loukili, Constr. Build. Mat. 121 (2016)

17. J. Saliba, A. Loukili, F. Grondin, J.-P. Regoin, Mat. Struct. 45, 9 (2012)

18. F. Grondin, H. Dumontet, A. Ben Hamida, G. Mounajed, H. Boussa, Cem. Concr. Res. 37, 10 (2007)

19. S. Fichant, C. La Borderie, G. Pijaudier-Cabot, Mechanics of Cohesive-frictional Materials 4 (4) (1999) 